\title{
Changes to the Domestic and Family Life of Health Personnel during the COVID-19 Pandemic
}

\author{
D Celali Kurt, (D) Arzu Altunçekiç Yıldırım \\ Department of Infectious Diseases and Clinical Microbiology, Faculty of Medicine, Ordu, Turkey
}

\section{ABSTRACT}

Objectives: Health personnel have experienced several challenges in the fight against the Coronavirus disease 2019 (COVID-19). They have experienced problems apart from work life and been forced to make sacrifices. This study was aimed to evaluate the changes in home and family life of health personnel during the COVID-19 pandemic.

Methods: Health personnel were reached in the using an electronic environment through social networks and communication applications, and they completed a survey containing 16 multiple choice questions from 9 May 2020 to 15 May 2020.

Results: Two thousand and fifty people participated in this study. Five hundred and ninety-one (28.8\%) participants were doctors, $903(44.0 \%)$ were nurses, and $556(27.1 \%)$ were other groups of health personnel. Of the 2013 responses, $126(6.3 \%)$ stayed elsewhere continuously, and $198(9.8 \%)$ sometimes stayed at home. Of 1993 responses, 767 (38.5\%) did not apply any isolation at home, while 827 (41.5\%) continuously implemented isolation measures. Eight hundred and forty (43.4\%) of 1937 responses continuously avoided hugging or kissing their partner and/or children. Of 2017 responses, 78 (3.9\%) stated that they or at least one of their family members developed the COVID-19 disease.

Please cite this article as: Kurt C, Altunçekiç Yıldırım A. Changes to the Domestic and Family Life of Health Personnel during the COVID-19 Pandemic. Anatol J Family Med 2021;4(2):146-152.

Address for correspondence: Dr. Celali Kurt. Department of Infectious Diseases and Clinical Microbiology, Faculty of Medicine, Ordu, Turkey

Phone: +90 5057266003

E-mail: celalikurt@yahoo.com

Received Date: 30.08 .2020

Accepted Date: 15.01.2021

Published online: 20.08.2021

@Copyright 2021 by Anatolian Journal of Family Medicine Available online at www.anatoljfm.org

OPEN ACCESS

Conclusion: There should be more aware of the difficulties experienced by health personnel outside of work life. The procedures outside of work life for personnel with duties during the pandemic should be discussed. Health management systems should provide more support for health employees on these topics and guide the determined procedures.

Keywords: COVID-19, family, health personnel

\section{INTRODUCTION}

An epidemic that occurred in China toward the end of 2019 and identified as linked to the novel Coronavirus (SARS-CoV-2) rapidly spread and transformed into a pandemic. ${ }^{[1,2]}$ Millions of patients in hundreds of countries have been affected by the pandemic and the deaths recorded are in the range of hundreds of thousands. ${ }^{[3]}$ As the clinical, virologic, and epidemiologic features and transmission routes of this initially uncertain disease have been uncovered, advances have been recorded in the domains of diagnosis, treatment, and transmission prevention. To prevent transmission to health personnel at increased risk, the importance of personal protective equipment and related regulations to use were clarified..$^{[4-6]}$ In spite of precautionary measures, many health personnel have been infected and unfortunately died, which has made the situation more distressing. ${ }^{[7,8]}$ Moreover, the occurrence of patients with asymptomatic disease and the finding that these patients may carry the virus for durations 
longer than two weeks has caused health personnel to apply many different isolation procedures within family life. ${ }^{[7,9]}$ This study was aimed to evaluate the changes in home and family life of health personnel during the COVID-19 pandemic.

\section{METHOD}

The survey of this cross-sectional study was open at web for 6 days from May 9, 2020 to May 15, 2020. The study included doctors, nurses, assisting health personnel and technical personnel from universities, training and research hospitals, state hospitals, private hospitals, and other organizations in Ordu, Istanbul and Ankara. The survey questions were sent to health personnel through social networks and communication applications via an electronic platform and were answered on a voluntary basis. A questionnaire consisting of 16 questions prepared by the researchers was used. There were 7 questions about demographic information (organization, occupation, department of employment, age, gender, marital status, and number of children) and 9 questions about the relating to the topic of research. Responses were multiple choice, with participants requested to mark only one choice.

Statistical analyses used the Statistical Package for Social Sciences (IBM SPSS for Mac, ver.21). The frequency and percentage were used in descriptive statistical methods. Chisquare analysis was used to compare independent groups containing categorical variables. A $p$ value $<0.05$ was considered to have statistical significance.

\section{RESULTS}

The survey was answered by 2050 health personnel. Sociodemographic and work-related characteristics of health professionals are summarized in Table 1.

Of the 2017 participants who responded to the question about transmission, 78 (3.9\%) stated that they or at least one of their family members developed the COVID-19 disease. The precautions applied by healthcare professionals are summarized Table 2.

There was no significant difference identified with respect to the development of the disease in themselves or family according to duty related to patients with COVID-19, doctor, nurse and other occupational groups, staying home or away after work, age groups, gender, and department of employment $(p=0.415, p=0.206, p=0.118, p=0.572$, $p=0.185$ and $p=0.319$, respectively). In the comparison's based on organization, there was a significant difference identified between private health organization employees and state hospital employees (20 (6.8\%) vs. 24 (2.8\%), respectively, $p=0.014$ ).
Table 1. Sociodemographic and work-related

characteristics of health professionals

n (\%)

Organization $(n=2050)$

State hospital

$846(41.3)$

University/TRH

$858(41.8)$

Private hospital

$295(14.4)$

Other

Occupation $(n=2050)$

Doctor

$591(28.8)$

Nurse

$903(44.0)$

Laboratory technician

$78(3.8)$

Anesthesia technician

38 (1.9)

Cleaning personnel

$161(7.9)$

Emergency medicine technician

$40(2.0)$

Other

$239(11.6)$

Do you work with COVID-19 patients? $(n=2017)$

Yes

$1417(70.3)$

No

$600(29.7)$

What do you do? $(n=1499)$

Emergency service and COVID-19 clinic

291 (19.4)

Clinic

224 (14.9)

Ward

640 (42.7)

Intensive care

344 (23.0)

Age groups $(n=2019)$

20 - 29 years

394 (19.5)

30 - 39 years

664 (32.9)

40 - 49 years

797 (39.5)

50 - 59 years

$164(8.1)$

Gender $(n=2020)$

Female

1422 (70.4)

Male

$598(29.6)$

Marital status $(n=2023)$

Single

Married

Number of children $(n=1982)$

None

481 (24.3)

One child

455 (23.0)

Two children

831 (41.9)

Three children

185 (9.3)

Four children or more $30(1.5)$

TRH: Training and research hospital.

A significant correlation was identified between the choice of continuously staying elsewhere with duties related to patients with COVID-19, being under 30 years of age, male gender, being single, and not having children $(p<0.001)$. 
Table 2. The precautions applied by healthcare professionals

n (\%)

Where did you stay during the pandemic?

I continuously stayed at home

1689 (83.9)

I sometimes stayed at home

198 (9.8)

$126(6.3)$

I was continuously away from home

$1236(77.9)$

215 (13.6)

26 (1.6)

$29(1.8)$

$80(5.1)$

Once a month

119 (5.9)

$104(5.2)$

$1740(86.4)$

Change clothes and shower

Did you isolate within your own home?

Not at all

767 (38.5)

399 (20.0)

$827(41.5)$

I continuously isolated

905 (61.9)

$557(38.1)$

I stayed in the same room with a mask

Is there anyone over 60 years at home?

No

$1621(80.5)$

Yes

Yes, but we stayed in separate houses

Did you avoid physical contact and kissing your

partner and children?

I have not avoided it

$157(8.1)$

I reduced but did not stop

$653(33.7)$

$287(14.8)$

$840(43.4)$

I completely avoided it

1939 (96.1)

$50(2.5)$

$10(0.5)$

$4(0.2)$

$14(0.7)$

My mother/father has been

Some variables were missing.

The data were presented as $\mathrm{n}(\%)$.

Single and childless respondents tended to avoid physical contact completely, while those who were married and had children tended to reduce contact rather than cut it completely. While avoidance of contact was the majority in par- ticipants over 50 and under 30 years of age, reduction of contact was predominant in participants aged $30-50$ years. Staying at home and physical contact status according to the sociodemographic characteristics of the participants are summarized Table 3.

While the rate of physicians who did not avoid contact was significantly higher than that of other occupational groups, the rate of avoiding contact completely was also found to be significantly lower. It was observed that state and university hospital employees preferred to reduce physical contact and private hospital employees preferred to cut it completely. Staff working in roles related to COVID-19 patients reduced or completely cut off physical contact at a higher rate. Staying at home and physical contact status according to the work-related characteristics of the participants are summarized in Table 4.

\section{DISCUSSION}

In the present study, an insignificant portion of health personnel (6.3\%) appeared to stay continuously in places other than their homes after work during the pandemic. However, when the proportion of those who sometimes stayed at home and sometimes elsewhere was added to this rate, it rose to $16.1 \%$. Even personnel who did not have duties related to patients with COVID-19 had rates of $2.5 \%$ and $7.7 \%$ for staying away from home continuously or intermittently. It appeared that mainly males, singles, and personnel under the age of 30 years tended to stay away from home. These results may be explained by the difficulty in staying away from home for individuals who are married or have children and women with family responsibilities. Though a significant difference was not identified in the present study between the place stayed in and development of infection in the health personnel themselves or family individuals, these rates may valuable in terms of reflecting the concerns and anxiety of personnel.

Health personnel may experience inadequacy related to high infection risk in the fight against COVID-19, insufficient protective precautionary measures against contamination, overwork, exhaustion, discrimination, isolation, and meeting with families. ${ }^{[10]}$ These may have outcomes like stress, anxiety, depression, insomnia, anger, and fear in severe situations. These mental health problems affect the attention, understanding, and decision-making of medical personnel but also affect interventions for COVID-19. Consequently, long-term control of the pandemic is important for preserving and supporting the mental health of health personnel. Although healthcare professionals often acknowledge the increased risk of infection as part of their chosen profession, those with family members who 


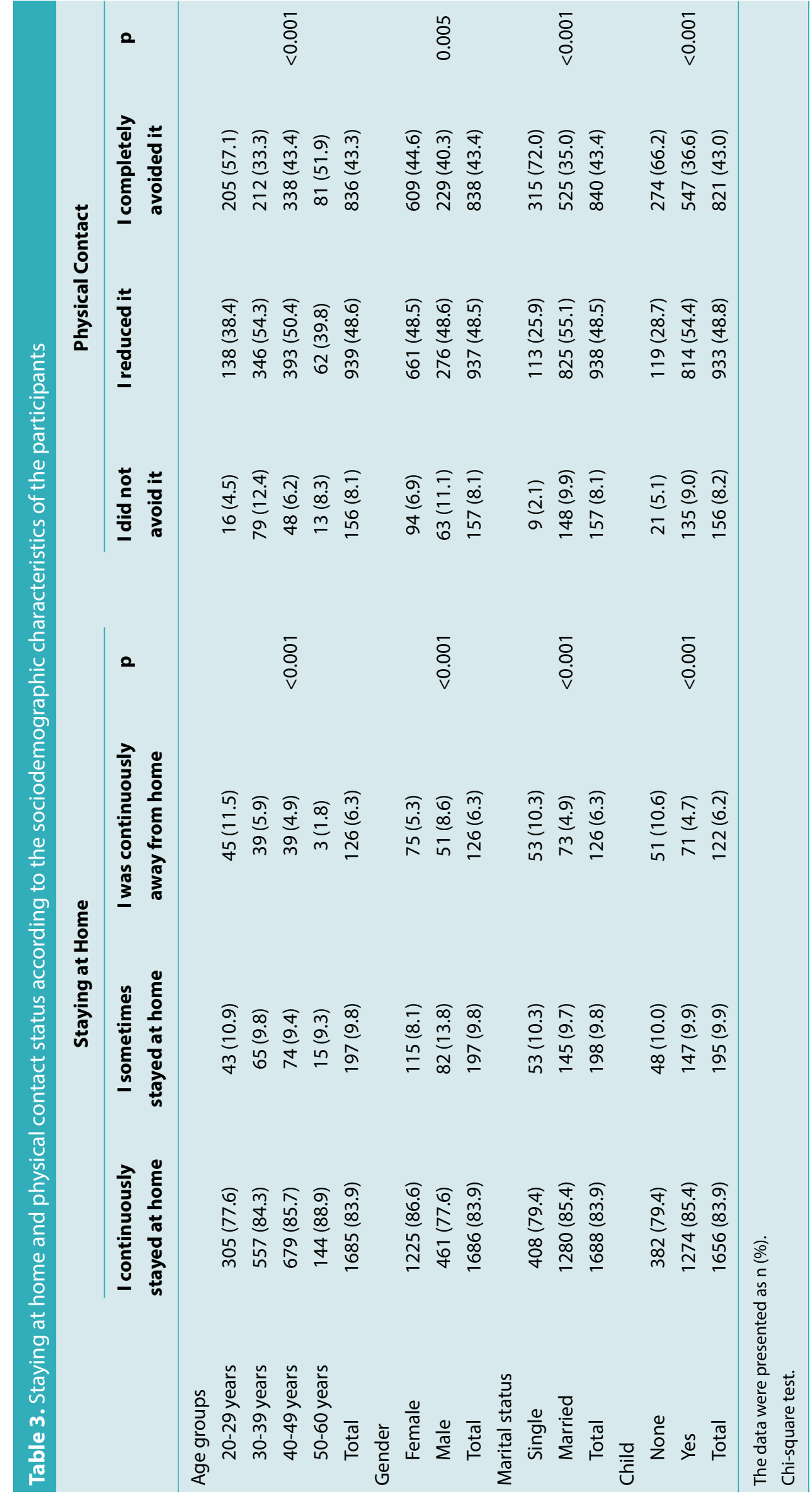

are elderly, immunocompromised, or have chronic illnesses are particularly concerned about domestic transmission. ${ }^{[11]}$ While many medical organizations offer clear recommendations, it is clear that more is needed to optimize safety in the current environment. Healthcare professionals may request that family members be given priority for testing, vaccination, and treatment. Providing reassurance to the family members of healthcare professionals will increase workforce confidence and productivity; however, the feasibility and advice of family priority has not yet been established.

In a study on health personnel in a Chinese pandemic hospital found a $50.4 \%$ frequency of depression, $44.6 \%$ anxiety, $34 \%$ insomnia, and a $71.5 \%$ frequency of psychological distress. This situation is thought to be caused by differing conditions in the workplace, concerns about viral spread, concerns about their personal health and that of their family members, and concerns about isolation. ${ }^{[12]}$ In a cross-sectional study of 1422 healthcare workers in Spain, it was found that $56.6 \%$ of the healthcare workers showed posttraumatic stress disorder, $58.6 \%$ showed anxiety disorder, $46 \%$ had depressive disorder symptoms, and $41.1 \%$ felt emotionally exhausted. ${ }^{[13]}$ In the COVID-19 pandemic, the most important cause of concern affecting the emotional and mental states of healthcare workers is the possibility of infecting family members and friends. ${ }^{[14,15]}$ Despite this, it has also been shown that good family relationships have a positive effect on anxiety and depression in healthcare workers. ${ }^{[14]}$ In a study conducted in Saudi Arabia, it was determined that healthcare workers are generally aware that they will have to work longer than dur- 


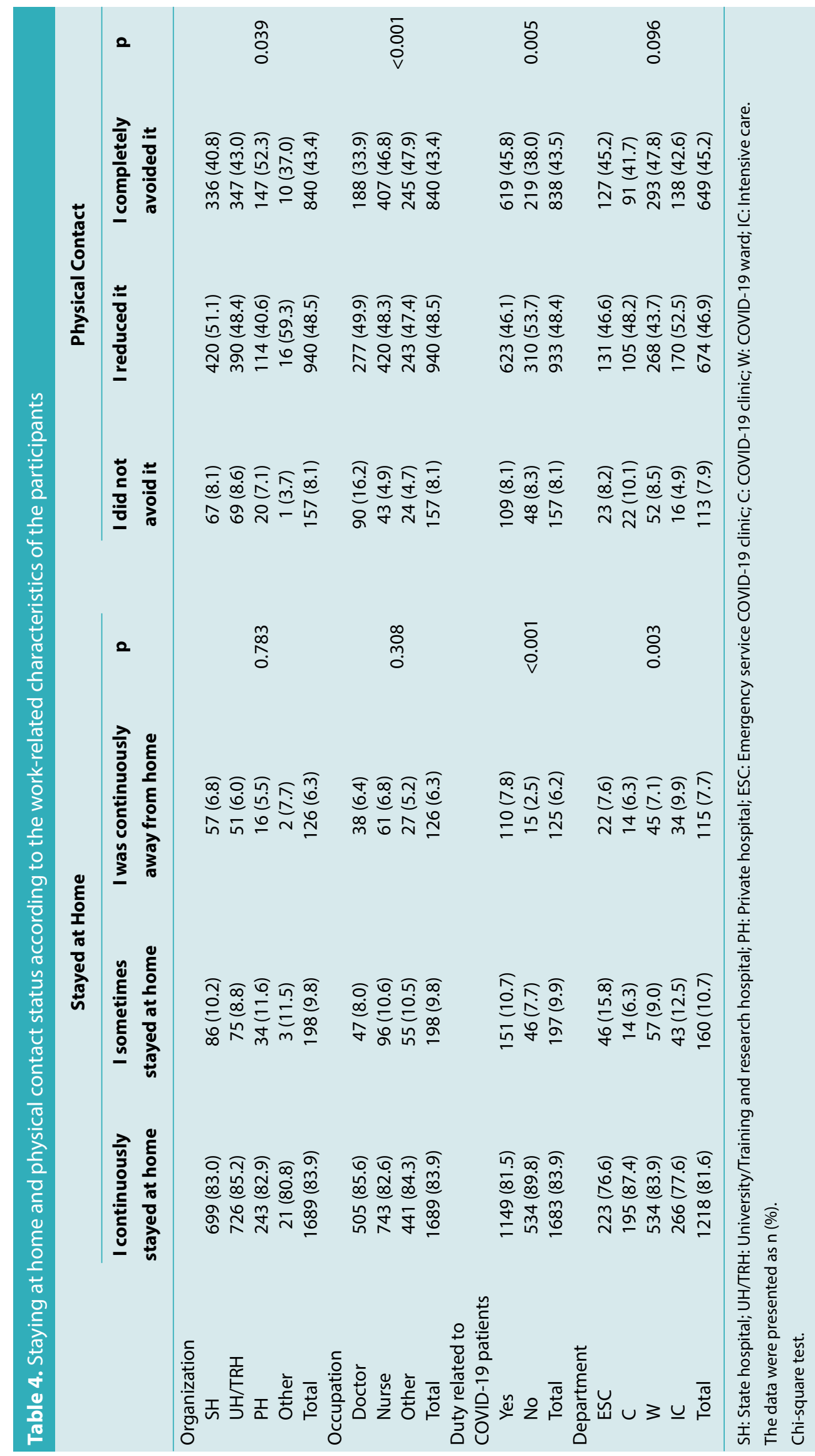

ing normal working conditions in cases of epidemics and disasters and are aware of their roles. [16] When asked about the cause of concern among healthcare workers during the COVID-19 outbreak, $57.5 \%$ expressed fear of their family members' health status, while only $35.1 \%$ expressed concern about their personal safety and that of other healthcare professionals.

It is clear that these concerns directed health workers toward new behaviors involving a variety of difficulties and sacrifices. However, the necessity of these practices performed out of concern has not been proven and requires debate and study.

It is known that the mortality rates of COVID-19 clearly increase with advanced age. ${ }^{[17,18]}$ Consequently, in Turkey there are limitations on people over 65 years being outside of the home. The reflection of the worry caused by this information is observed in some health workers separating their homes from that of family members over 60 years of age. However, an insignificant frequency $(13.9 \%)$ continued to live together. The presence of asymptomatic COVID-19 carriers led health personnel to continue worrying even when they did not feel sick. ${ }^{[19,20]}$ Screening with polymerase chain reaction (PCR) of 565 Japanese citizens evacuated from Wuhan identified positive results for 12 individuals. ${ }^{[21]}$ Five individuals of these were asymptomatic and it is estimated that the disease may progress silently in over $40 \%$ of patients with COVID- 19 . Screening of health workers in England reported that $27 \%$ of 44 health workers with a positive 
PCR test were asymptomatic. ${ }^{[22]}$ Routine screening is still not performed on symptom-free health personnel in our country. Screening with molecular methods is performed after development of symptoms or risky contact with a patient with COVID-19. Moreover, there are studies showing that the main transmission route of infection of droplets may travel further distances than what is known. ${ }^{[23]}$ Consequently, the majority of health workers staying at home practiced a meticulous "home entry procedure" and after this, were identified to apply precautionary measures that may have destructive psychological outcomes like staying in separate rooms from that of family members, using masks in the same environment and reducing or fully stopping physical contact with partners, parents, and children.

The epidemic also had significant psychological effects on the family members of healthcare workers. In one study, anxiety and depression symptoms were found in one third of the participants who were relatives of healthcare workers. ${ }^{[24]}$ In the current study, while the contact of the healthcare worker with the definite or suspected patient with COVID-19 and long working hours were risk factors for depression and anxiety; the use of personal protective equipment was determined as a protective factor.

The limitations of the present study were the participants had to access the survey in an electronic platform, the multiple-choice responses and that only one choice could be selected. These features limit the participants' self-expression and caused some questions to be left unanswered by many respondents. Many situations that can be investigated related to the topic, concerns representing the basis of participant practices and psychological outcomes could not be questioned. The access method of the survey for medical workers caused uncertainty about the population in the study. Again, the uncertain and broad study population may contribute to representing the country in general rather than just certain cities. Further, there are no studies on similar topics reflecting data from other countries in the literature to compare with the results of our screening.

\section{CONCLUSION}

This data may guide health managers in their duties related to planning and preparation related to the topic. In Turkey, Ministry of Health guidelines categorized risky contact that health workers are exposed to as low, moderate, and high risk and published isolation and prophylaxis approaches to be followed afterwards based on the contact risk. However, protocols related to where health personnel should stay after work or home entry procedures or relationships with family members are uncertain and left to the employee's own choice. It will be beneficial to discuss these topics in the scientific environment and determine recommendations. In Turkey, many health organizations allocated dormitories, hotels, and guest houses for health workers to stay in if desired. It is known through the media and personal witnesses that many health workers did not stay in their own homes in order to protect family members. However, there is no data about the frequency of use for this method. From this aspect, the present study has the feature of being the first study to provide data about this topic in our country. Moreover, there is no data in the literature about new precautionary attitudes and behavior in family life practices by health workers who chose to stay at home. In addition to difficulties experienced in working life, it is thought that this data is important in terms of illuminating the sacrifices made in social life by health personnel in pandemic.

\section{Disclosures}

Peer-review: Externally peer-reviewed.

Conflict of Interest: The authors have no conflict of interest relevant to this study to declare.

Funding: No financial support.

Ethics Committee Approval: The approval for the research was obtained from Ordu University Faculty of Medicine Ethics Committee. (Approval date: May 14, 2020, and Approval number:103).

Authorship Contributions: Concept -C.K.; Design - C.K.; Supervision -C.K., A.A.Y.; Materials - C.K.; Data collection \&/or processing - C.K., A.A.Y.; Analysis and/or interpretation - C.K.; Literature search - C.K.; Writing - C.K.; Critical review - C.K., A.A.Y.

\section{REFERENCES}

1. World Health Organization. Pneumonia of unknown cause China. Available at: https://www.who.int/csr/don/05-january2020-pneumonia-of-unkown-cause-china/en/. Accessed May 16, 2020.

2. World Health Organization. Novel coronavirus - China. Available at: https://www.who.int/csr/don/12-january-2020-novel-coronavirus-china/en/. Accessed May 16, 2020.

3. World Health Organization. Coronavirus disease (COVID-19) situation report - 112. Available at: https://www.who.int/docs/ default-source/coronaviruse/situation-reports/20200511-covid-19-sitrep-112.pdf?sfvrsn=813f2669_2. Accessed May 16, 2020.

4. World Health Organization. Rational use of personal protective equipment (PPE) for coronavirus disease (COVID-19). Available at: https://apps.who.int/iris/bitstream/handle/10665/331498/WHO-2019-nCoV-IPCPPE_use-2020.2eng.pdf. Accessed May 16, 2020.

5. Cook TM. Personal protective equipment during the coronavirus disease (COVID) 2019 pandemic - a narrative review. An- 
aesthesia 2020;75(7):920-7. [CrossRef]

6. Li Q, Guan X, Wu P, Wang X, Zhou L, Tong Y, et al. Early transmission dynamics in Wuhan, China, of novel coronavirus-infected pneumonia. N Engl J Med 2020;382(13):1199-207. [CrossRef]

7. Wu Z, McGoogan JM. Characteristics of and Important Lessons From the Coronavirus Disease 2019 (COVID-19) Outbreak in China: Summary of a Report of 72314 Cases From the Chinese Center for Disease Control and Prevention. JAMA 2020;323(13):1239-42. [CrossRef]

8. Remuzzi A, Remuzzi G. COVID-19 and Italy: what next? Lancet 2020;395(10231):1225-8. [CrossRef]

9. Hu Z, Song C, Xu C, Jin G, Chen Y, Xu X, et al. Clinical characteristics of 24 asymptomatic infections with COVID-19 screened among close contacts in Nanjing, China. Sci China Life Sci 2020;63(5):706-11. [CrossRef]

10. Kang L, Li Y, Hu S, Chen M, Yang C, Yang BX, et al. The mental health of medical workers in Wuhan, China dealing with the 2019 novel coronavirus. Lancet Psychiatry 2020;7(3):e14.

11. Adams JG, Walls RM. Supporting the health care workforce during the COVID-19 global epidemic. JAMA 2020;323(15):143940. [CrossRef]

12. Lai J, Ma S, Wang Y, Cai Z, Hu J, Wei N, et al. Factors associated with mental health outcomes among health care workers exposed to coronavirus disease 2019. JAMA Netw Open 2020;3(3):e203976. [CrossRef]

13. Luceño-Moreno L, Talavera-Velasco B, García-Albuerne $Y$, Martín-García J. Symptoms of posttraumatic stress, anxiety, depression, levels of resilience and burnout in spanish health personnel during the COVID-19 pandemic. Int J Environ Res Public Health 2020;17(15):5514. [CrossRef]

14. Dong ZQ, Ma J, Hao YN, Shen XL, Liu F, Gao Y, et al. The social psychological impact of the COVID-19 pandemic on medical staff in China: A cross-sectional study. Eur Psychiatry 2020;63(1):e65. [CrossRef]

15. Wu W, Zhang Y, Wang P, Zhang L, Wang G, Lei G, et al. Psycho- logical stress of medical staffs during outbreak of COVID-19 and adjustment strategy. J Med Virol 2020;92(10):1962-70.

16. Almaghrabi RH, Alfaraidi HA, Al Hebshi WA, Albaadani MM. Healthcare workers experience in dealing with Coronavirus (COVID-19) pandemic. Saudi Med J 2020;41(6):657-60. [CrossRef]

17. Livingston E, Bucher K. Coronavirus Disease 2019 (COVID-19) in Italy. JAMA 2020;323(14):1335. [CrossRef]

18. Vital surveillances: the epidemiological characteristics of an outbreak of 2019 novel coronavirus diseases (COVID-19) China, 2020. Available at: http://weekly.chinacdc.cn/en/article/id/e53946e2-c6c4-41e9-9a9b-fea8db1a8f51. Accessed May 17, 2020.

19. Bai Y, Yao L, Wei T, Tian F, Jin DY, Chen L, et al. Presumed asymptomatic carrier transmission of COVID-19. JAMA. 2020 Apr 14;323(14):1406-7. [CrossRef]

20. Rothe C, Schunk M, Sothmann P, Bretzel G, Froeschl G, Wallrauch C, et al. Transmission of 2019-nCoV infection from an asymptomatic contact in Germany. $\mathrm{N}$ Engl J Med 2020;382(10):970-1. [CrossRef]

21. Nishiura H, Kobayashi T, Miyama T, Suzuki A, Jung SM, Hayashi $\mathrm{K}$, et al. Estimation of the asymptomatic ratio of novel coronavirus infections (COVID-19). Int J Infect Dis 2020;94:154-5.

22. Treibel TA, Manisty C, Burton M, McKnight Á, Lambourne J, Augusto JB, et al. COVID-19: PCR screening of asymptomatic health-care workers at London hospital. Lancet 2020;395(10237):1608-10. [CrossRef]

23. Bahl P, Doolan C, de Silva C, Chughtai AA, Bourouiba L, MacIntyre CR. Airborne or droplet precautions for health workers treating COVID-19? J Infect Dis. 2020 Apr 16. doi: 10.1093/ infdis/jiaa189. [Epub ahead of print]. [CrossRef]

24. Ying Y, Ruan L, Kong F, Zhu B, Ji Y, Lou Z. Mental health status among family members of health care workers in Ningbo, China, during the coronavirus disease 2019 (COVID-19) outbreak: a cross-sectional study. BMC Psychiatry 2020;20(1):379. [CrossRef] 